\title{
Penggunaan Batu Gunung Patangdo Kapa' Kabupaten Tana Toraja Dalam Campuran AC-BC
}

\author{
Noviana Debi¹, Rais Rachman*2, Alpius ${ }^{\star 3}$ \\ *1 Mahasiswa Program Studi Teknik Sipil, Universitas Kristen Indonesia Paulus, Makassar, Indonesia \\ novianadebi074@gmail.com \\ *2,3 Dosen Program Studi Teknik Sipil, Universitas Kristen Indonesia Paulus, Makassar, Indonesia \\ rais.rachman@gmail.com dan alpiusnini@gmail.com
}

\begin{abstract}
ABSTRAK
Tujuan penelitian ini untuk menguji secara laboratorium penggunaan Batu Gunung Patangdo Kapa' Kabupaten Tana Toraja sebagai campuran AC-BC dengan memvariasikan penggunaan aspal dengan kadar 5,00\% 5,50\% 6,00\% 6,50\% $7,00 \%$ serta menguji ketahanan campuran terhadap suhu perendaman. Metodologi pada penelitian ini menggunakan metode yang terdiri dari serangkaian uji karakteristik agregat kasar, halus, filler serta aspal selanjutnya merancang komposisi campuran kemudian dilanjutkan dengan membuat benda uji yaitu campuran AC-BC melalui percobaan MIX Design untuk memperoleh nilai Indeks Kekuatan Sisa dengan penggunaan Kadar Aspal Optimum. Dari hasil penelitian yang dilaksanakan di Laboratorium Jalan dan Aspal Fakultas Teknik Jurusan Teknik Sipil Universitas Kristen Indonesia Paulus Makassar, sudah menunjukkan bahwa karakteristik bahan perkerasan berupa Batu Gunung Patangdo Kapa' Kabupaten Tana Toraja sudah memenuhi Standar Spesifikasi Bina Marga 2018 sebagai bahan dalam perkerasan jalan khususnya pada campuran AC-BC melalui pengujian dengan karakteristik dan dengan kadar aspal 5,00\%, 5,50\%, 6,00\%, $6,50 \%$ dan 7,00\%. Hasil uji Marshall Immersion campuran AC-BC yang menggunakan kadar aspal optimum 6,00 \% diperoleh Indeks Kekuatan Sisa ( IKS)/Durabilitas sebesar 93,47 \%. Jadi ini menunujukan bahwa pengujian memenuhi persayatan yaitu minimal 90\% dan memenuhi Spesifikasi Bina Marga 2018.
\end{abstract}

Kata kunci : Karakteristik Agregat, Komposisi Campuran AC-BC, Marshall Test

\begin{abstract}
The purpose of this study was to laboratory test the use of Mount Patangdo Kapa 'Rock in Tana Toraja Regency as a mixture of $\mathrm{AC}-\mathrm{BC}$ by varying the use of asphalt with a content of $5.50 \% 5.50 \% 6.50 \% 6.50 \% 7.00 \%$ and testing the resistance. mixture to immersion temperature. The methodology in this study used a method consisting of a series of characteristic tests for coarse, fine, filler and asphalt aggregates, then designing the composition of the mixture, then proceeding to make the test object, namely the AC-BC mixture through the MIX Design experiment to obtain the value of the Residual Strength Index using the optimal asphalt content. . From the results of research carried out at the Road and Asphalt Laboratory of the Faculty of Engineering, Department of Civil Engineering, Paul Makassar Christian University of Indonesia, it has shown that the characteristics of the pavement material in the form of Patangdo Kapa 'Mountain Rock' Tana Toraja Regency have met the 2018 Highways Standard Specification as material in road pavement, especially in AC-BC mixture through testing with characteristics and with asphalt content of $5.00 \%, 5.50 \%, 6.00 \%, 6.50 \%$ and $7.00 \%$. Marshall immersion test results of AC-BC mixture using optimum asphalt content of $6.00 \%$ obtained a residual strength index (IKS) / durability of $93.47 \%$. So this shows that the test meets the requirements of at least $90 \%$ and meets the 2018 Highways Specifications.
\end{abstract}

Keywords: Aggregate Characteristics, mix AC-BC Composition, Marshall Test 


\section{PENDAHULUAN}

Jalan raya merupakan prasarana transportasi yang sangat berpengaruh pada perkembangan sosial dan ekonomi masyarakat. Fungsi utama jalan raya adalah sebagai prasarana melayani pergerakan lalu lintas secara aman, nyaman, cepat dan ekonomis. Peningkatan jumlah kendaraan yang besar namun tidak diikuti dengan kualitas perkerasan jalan yang baik akan menyebabkan jalan banyak mengalami kerusakan. Dengan meningkatnya pembangunan prasarana transportasi yang seuntukmakin meningkat maka perlu upaya untuk meningkatkan kualitas perkerasan jalan dilakukan salah satunya dengan menggunakan agregat yang baik dan layak guna mendapatkan kualitas perkerasan yang baik.

Untuk mengurangi biaya konstruksi, agregat sedapat mungkin diperoleh dari sumber terdekat dari lokasi pekerjaan. Lokasi sumber agregat bisa terdapat di gunung atau perbukitan dan bisa juga dari sungai. Agregat yang digunakan pada perkerasan jalan sebisa mungkin agregat yang terdapat disekitaran lokasi pekerjaan agar lebih efisien baik dari segi waktu dan biaya dibandingkan dengan mendatangkan material dari luar daerah karena itu hanya akan memicu pemborosan.

Dalam pelaksanaan penelitian, penggunaan material diambil dari Gunung Patangdo Kapa' Kabupaten Tana Toraja. Gunung ini memiliki sumber material yang cukup memadai dalam pembuatan sarana transportasi disekitar gunung tersebut. Karena agregat yang terdapat di Gunung Patangdo Kapa' belum dimanfaatkan secara maksimal sehingga agregat yang terdapat pada gunung ini hanya dimanfaatkan oleh masyarakat disekitar lokasi pada bangunan berskala kecil, seperti pondasi dan turap (dinding penahan). Maka dari itu agregat yang ada pada gunung tersebut menjadi bahan penelitian lapisan perkerasan jalan pada lapisan Asphalt Concrete - Binder Course (AC-BC) agar dapat dimanfaatkan semaksimal mungkin oleh masyarakat terutama pemerintah setempat. Tetapi sebelum digunakan, sifat fisik dan mekanik dari agregat Gunung Patangdo Kapa' Kabupaten Tana Toraja perlu dilakukan pengujian material melalui Laboratorium yang meliputi pengujian karakteristik agregat, karakteristik aspal dan berat jenis filler, komposisi dan karakteristik campuran apakah layak digunakan pada perkerasan jalan pada campuran AC-BC.
Penelitian sebelumnya yang melakukan penelitian tentang material lokal antara lain pemanfaatan agregat Sungai Wanggar Kabupaten Nabire sebagai bahan campuran AC-WC dan AC-BC [1]. Penggunaan Agregat Sungai Batu Tiakka' dalam Campuran AC-BC [2]. Pemanfaatan Batu Gunung Posi'padang Balla Kabupaten Mamasa Sebagai Campuran AC-BC [3]. Studi Penggunaan Agregat Sungai Bittuang Sebagai Bahan Campuran AC-WC [4]. Pemanfaatan Batu Gunung Bottomale Toraja Utara sebagai Campuran Laston [5]. Pemanfaatan Batu Gunung Ambeso pada Campuran AC-Base [6]

Selain itu peneliti yang meneliti tentang Aspal Beton (AC) antara lain Pengaruh Variasi tumbukan terhadap Indeks Kekuatan sisa AC-WC [7]. Kajian penggunaan Abu Ampas sebagai pengganti filler terhadap Karakteristik Aspal Beton [8]. Pengaruh penambahan serat ijuk Terhadap ketahanan campuran Laston AC-WC [9].

Tujuan penelitian ini untuk menguji secara laboratorium penggunaan Batu Gunung Patangdo Kapa' Kabupaten Tana Toraja sebagai campuran AC-BC dengan memvariasikan penggunaan aspal dengan kadar 5,00\% 5,50\% 6,00\% 6,50\% 7,00\% serta menguji ketahanan campuran terhadap suhu perendaman.

\section{METODE PENELITIAN}

\section{Lokasi material}

Material didapatkan dari Gunung Patangdo Kapa' yang terletak di desa Lembang Gasing, Kecamatan Mengkendek, Kabupaten Tana Toraja.

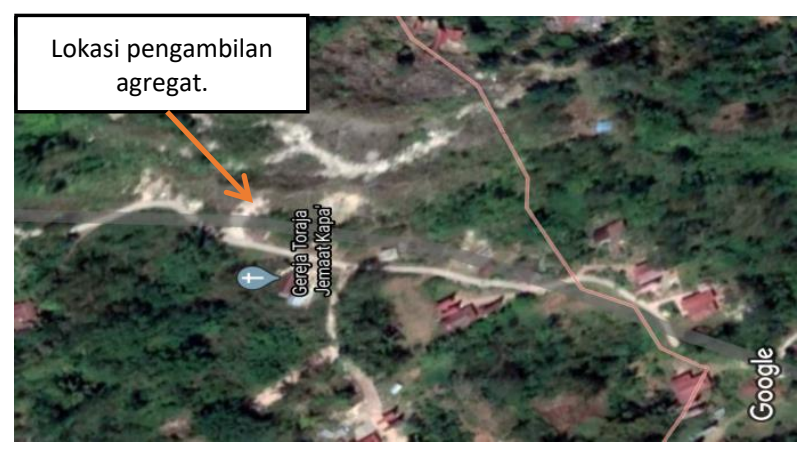

Gambar 1. Lokasi Penelitian

\section{Pemeriksaan Karakteristik Agregat}

Pemeriksaan karakteristik agrgat didasarkan pada SNI sesuai dengan spesifikasi Bina Marga 2018 [10].

Dalam melaksanakan penelitian, ada beberap jenis pengujian yang akan dilakukan guna untuk menentukan ukuran butir bahan yang dinyatakan 
dalam grafik untuk mendapatkan pembagian butir dari tiap-tiap saringan.

Analisa saringan adalah untuk menentukan presentase jumlah berat butiran agregat yang dinyatakan lolos dari saringan yang nantinya jumlah presentase dibawa kedalam grafik pembagian butiran. Kemudian memperlihatkan pembagian butir (gradasi) dengan saringan dan tujuannya memperoleh persentase jumlah butiran.

Pemeriksaan kadar lumpur yang tujuannya mengetahui jumlah banyak kadar lumpur dari material kemudian dinyatakan dalam persen.

Pemeriksaan Berat Jenis Curah (Bulk) dan Penyerapan Air Agregat kasar yang tujuannya untuk menetukan nilai berat jenis dan penyerapan.

Pengujian Keausan (Abration) dengan menggunakan Mesin Los Angeles yang tujuannya meningkatkan tingkat keausan aggregat dengan dengan nomor saringan yang sudah ditentukan dengan berat sebelumnya yang nantinya dinyatakan dalam persen.

Pemeriksaan Partikel Pipih dan Lonjong yang tujuannyaa untuk menentukan indeks kepipihan dan kelonjongan agregat yang nantinya akan dinyatakan dalam persen.

Pengujian Kelekatan Agregat Terhadap Aspal yang tujuannga menentukan kelekatan agregat terhadap aspal. Kelekatan agregat terhadap aspal ialah presentase luas permukaan batuan yang tertutup aspal terhadap keseluruhan luas permukaan.

\section{Pemeriksaan Karakteristik Aspal}

Dalam pelaksanaanya metodologi yang digunakan adalah Pengujian Penetrasi pada $25^{\circ} \mathrm{C}$ yang tujuannya menentukan tingkat kekerasan aspal yang diketahui dari berapa dalamnya jarum masuk ke dalam aspal dengan suhu, dengan beban dan waktu tertentu.

Pengujian Titik Nyala $\left({ }^{\circ} \mathrm{C}\right)$. Berdasarkan hasil pengujian Titik Nyala didapatkan nilai rata-rata $290^{\circ} \mathrm{C}$ yang merupakan hasil yang masuk dalam syarat yang ditentukan dalam dalam standar Spesifikasi yaitu $\geq 232^{\circ} \mathrm{C}$ dapat dilihat pada.

Pengujian Berat Jenis (SNI 2441:2011), yang tujuannya mengetahui berat jenis aspal terhadap air suling.

Pengujian Titik Lembek $\left({ }^{\circ} \mathrm{C}\right)$ (SNI 2434:2011), yang tujuannya untuk menentukan pada suhu berapa aspal mulai lembek atau mencair.
Pengujian Daktilitas pada $25^{\circ} \mathrm{C}$ yang tujuannya mengetahui kekenyalan aspal yang nantinya akan dinyatakan dengan panjang pemuluran aspal yang dapat tercapai hingga sebelum putus.

Pengujian Berat yang hilang (\%) (SNI-06-24411991), yang tujuannya untuk mengetahui minyak yang hilang pada aspal akibat adanya pemanasan berulang yang tujuannya mengukur perubahan kinerja aspal akibat kehilangan berat

\section{Pemeriksaan Berat Jenis Filler}

Pemeriksaan Berat Jenis Filler yang tujuannya menentukan berat jenis Filler yang nantinya akan dipakai dalam bahan pengisi campuran aspal ACBC.

\section{Perencanaan Campuran}

Rancangan campuran AC-BC yang nantinya digunakan harus berdasar pada metode grafis dan analitis yaitu dengan menggunakan tabel batasan spesifikasi gradasi campuran lalu menentukan gradasi ideal yaitu nilai tengah dari masing-masing batasan.

Selanjutnya dilakukan perhitungan komposisi stiap fraksi serta kebutuhan aspal campuran kemudian digambarkan dalam bentuk grafik gradasi dan dicermati gradiasi masuk pada batasan gradiasi yang sesuai dengan standard spesifikasi.

Berikut adalah table rancangan komposisi campuran.

Tabel 1. Rancangan Komposisi Campuran

\begin{tabular}{|c|c|c|c|}
\hline \multicolumn{2}{|c|}{ Ukuran Saringan } & \multirow{2}{*}{$\begin{array}{c}\text { Spesifikasi BM } \\
2018 \\
(\%)\end{array}$} & \multirow{2}{*}{$\begin{array}{c}\text { Gradasi } \\
\text { Rancangan } \\
(\%)\end{array}$} \\
\hline Inchi & $\mathrm{Mm}$ & & \\
\hline $11 / 2$ & 37,5 & & \\
\hline 1" & 25 & 100 & 100 \\
\hline 3/4" & 19 & $90-100$ & 95 \\
\hline $1 / 2^{\prime \prime}$ & 12,5 & $75-90$ & 82,5 \\
\hline 3/8" & 9,5 & $66-82$ & 74 \\
\hline No.4 & 4,75 & $46-64$ & 55 \\
\hline No.8 & 2,36 & $30-49$ & 39,5 \\
\hline No.16 & 1,18 & $18-38$ & 28 \\
\hline No.30 & 0,6 & $12-28$ & 20 \\
\hline No.50 & 0,3 & $7-20$ & 13,5 \\
\hline No.100 & 0,15 & $5-13$ & 9 \\
\hline No.200 & 0,075 & 4.-8 & 6 \\
\hline
\end{tabular}

\section{Komposisi campuran}

Jika bahan yang akan digunakan telah memenuhi spesifikasi maka selanjutnya menghitung komposisi campuran dan jumlah benda uji. 
Berikut adalah tabel komposisi campuran disertai dengan porsi filler yang akan digunakan.

Tabel 2. Komposisi campuran

\begin{tabular}{|c|c|c|c|c|c|c|}
\hline \multirow{2}{*}{ Material } & \multirow{2}{*}{ Uk.Saringan } & \multicolumn{5}{|c|}{ Kadar Aspal } \\
\hline & & $5,00 \%$ & $5,50 \%$ & $6,00 \%$ & $6,50 \%$ & $7,00 \%$ \\
\hline \multirow{4}{*}{ Agregat Kasar } & $3 / 4 "$ & & & & & \\
\hline & $1 / 2 "$ & 4282 & 4300 & 4282 & 4264 & 4245 \\
\hline & $3 / 8 "$ & $4<, 0<$ & 40,00 & $4<, 0<$ & $4<, 04$ & \\
\hline & No.4 & & & & & \\
\hline \multirow{6}{*}{ Agregat Halus } & No.8 & & & & & \\
\hline & No.18 & & & & & \\
\hline & No.30 & 4627 & $46 \cap 0$ & 4573 & 4545 & 4518 \\
\hline & No.50 & 46,27 & 46,00 & 45,73 & 45,45 & 45,18 \\
\hline & No.100 & & & & & \\
\hline & No.200 & & & & & \\
\hline Filler & & 5,55 & 5,50 & 5,45 & 5,41 & 5,36 \\
\hline
\end{tabular}

Tabel 3. Jumlah benda uji

\begin{tabular}{ccc} 
Kadar Aspal & $\begin{array}{c}\text { Marshall } \\
\text { Konvensional }\end{array}$ & $\begin{array}{c}\text { Marshall } \\
\text { Immertion }\end{array}$ \\
\hline $5,00 \%$ & 3 & \\
$5,50 \%$ & 3 & 3 \\
$6,00 \%$ & 3 & \\
$6,50 \%$ & 3 & \\
$7,00 \%$ & 3 & \\
\hline
\end{tabular}

\section{Pengujian Marshall Konvensional}

Sampel yang nantinya diuji pada Marshall Konvensional dilakukan yang tujuannya untuk mengetahui kemampuan campuran terhadap lama perendaman, suhu, dan air dengan jumlah sampel 5 yang dimulai dari kadar aspal $5,00 \%$ dengan kenaikan kadar aspal 0,5\% masing-masing sampel dengan prosedurnya sama dengan pengujian pada Marshall standar untuk campuran Hot mix.

\section{Penentuan Kadar aspal optimum}

Setelah melakukan pengujian Marshall Konvesional, selanjutnya yang dilakukan adalah menganalisis karekteristik Marshall Konvensional yang tujuannya menentukan Kadar Aspal Optimum. Yang kemudian melakukan pembuatan benda uji pada Kadar Aspal Optimum campuran AC-BC yang nantinya akan diuji pada Marshall Immersion.

\section{Pengujian Marshall Immersion}

Mengetahui kemampuan campuran terhadap lama perendaman, suhu, dan air dengan jumlah sampel 5 yang dimulai dari kadar aspal 5,00\% dengan kenaikan kadar aspal 0,5\% masing-masing sampel dengan prosedurnya sama dengan pengujian pada Marshall standar untuk campuran Hot mix.

\section{ANALISIS DAN PEMBAHASAN}

1. Karakteristik Material

a. Agregat

Berikut hasil uji karakteristik agregat kasar dan halus.

Abrasi Mesin Los Angeles (Lampiran A1-A4), didapatkan nilai ketahanan keausan agregat kasar terhadap masing-masing komponen yang terdiri atas komponen A 2,1\%, B 2,42\%, C 2,08\% dan D $2,54 \%$. Dengan melihat nilai dari masing-masing komponen sudah menujukkan bahwa material dari gunung Patangdo Kapa' memenuhi Standar Spesifikasi.

Berat Jenis (Bulk) dan Penyerapan Air Agregat Kasar dengan dua sampel yang dipakai, diperoleh nilai sebagai berikut: Bulk density 2,65, berat jenis SSD 2,6, berat jenis semu 2,76 dan Penyerapan Air adalah $1,46 \%$. Dari nilai tersebut dapat disimpulkan bahwa semuanya memenuhi standard spesifikasi.

Hasil pengujian Analisa saringan dapat dilihat pada gambar 2. 


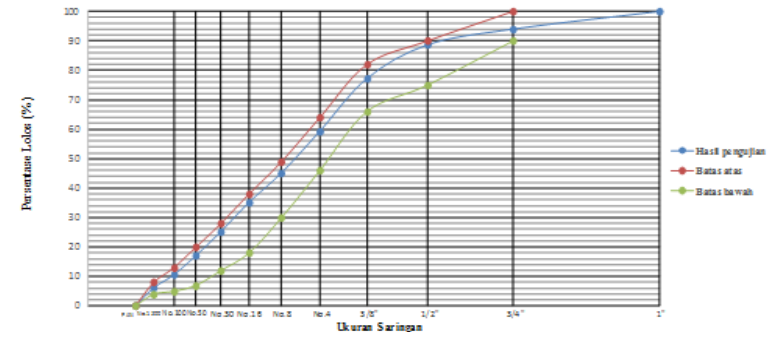

\section{Gambar 2. Hasil pengujian Analisa saringan}

Dengan melihat gambar diatas dapat dilihat hasil analisa saringan yaitu gradasi material yang disertai dengan serta spesifikasinya. Ini menunujukan bahwa agregat dari gunung Patangdo Kapa' layak digunakan dan sesuai dengan standard Spesifikasi Bina Marga.

Partikel Kepipihan dan Kelonjonganyang memiliki hasil sebagai berikut; untuk partikel pipih diperoleh $3 \%, 2,80 \%, 2,40 \%$, dan $0 \%$. Dan untuk artikel lonjong 2,70\%, 2,20\%, 2,10\% dan $0 \%$.

Hasil pengujian Kadar lumpur yang menunjukkan hasil uji kadar lumpur rata-rata untuk nilai Sand Equivalen (SE) adalah 97,78\% dan kadar lumpurnya $2,22 \%$ yang hasilnya memenuhi standard Spesifikasi.

Kelekatan Agregat Terhadap Aspal hanya bias diamati tanpa melakukan perhitungan yang nilainya diperoleh dengan berdsar pada luas permukaan fraksi yang ditutupi aspal. Dengan begtu pada pengamatan didapatkan nilai 95\% untuk aspal dapat melekat dengan baik dan sempurna pada agregat.

\section{b. Aspal}

Jadi dalam pelaksanaan penelitian, penggunaan aspal adalah aspal minyak penetrasi 60/70.

\section{Marshall Konvensional}

Benda uji yang akan dibuat dengan kadar aspal $5,00 \%, 5.50 \%, 6,00 \%, 6,50 \%$, dan $7,00 \%$ dapat dilihat pada table berikut ini.

Tabel 4. Bulk Spesific Gravity dan Effective Spesific Gravity.

\begin{tabular}{llllll}
\hline & \multicolumn{5}{c}{ Campuran AC-BC } \\
\cline { 2 - 6 } Kadar Aspal (\%) & 5,00 & 5,50 & 6,00 & 6,50 & 7,00 \\
\hline $\begin{array}{l}\text { Bulk Spesific } \\
\text { Gravity Agregat }\end{array}$ & 2,75 & 2,77 & 2,78 & 2,80 & 2,81 \\
$\begin{array}{l}\text { Effective } \\
\begin{array}{l}\text { Spesific Gravity } \\
\text { Agregat }\end{array}\end{array}$ & 2,82 & 2,83 & 2,85 & 2,86 & 2,88 \\
\hline
\end{tabular}

Berikut adalah hasil uji karakteristik marshall konvensional yang terdiri atas Stabilitas, VIM (Void in Mix), Flow, VMA.

Tabel 5. Nilai Karakteristik Marshall Konvensional

\begin{tabular}{cccccc} 
& \multicolumn{5}{c}{ Karakteristik Marshall Konvensional dan Penyerapan } \\
\cline { 2 - 6 } Kadar Aspal (\%) & $3-5(\%)$ & Min 800 $(\mathrm{kg})$ & Min 65 $(\%)$ & $2-4(\mathrm{~mm})$ & Min 14 (\%) \\
\cline { 2 - 6 } & VIM & Stabilitas & VFB & Flow & VMA \\
\hline 5.00 & 4.76 & 1253.58 & 68.04 & 2,78 & 14,88 \\
5.50 & 4.51 & 1714.62 & 71.57 & 2.50 & 15,85 \\
6.00 & 4.07 & 1916.34 & 75.56 & 2.25 & 16,67 \\
6.50 & 3.53 & 1796.27 & 79,70 & 2.60 & 17,39 \\
7.00 & 3.16 & 1580.14 & 82,68 & 3.10 & 18,26 \\
\hline
\end{tabular}

\section{a. Stabilitas}

Berikut hasil uji grafik kadar aspal dengan stabilitas.

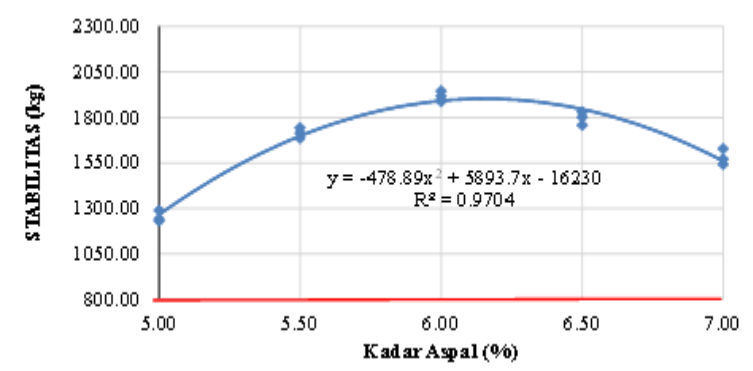

Gambar 3. Hubungan antara kadar aspal dengan Stabilitas
Dengan melihat gambar 3, dapat dilihat bahwa stabilitas menurun dikadar aspal 5,00-5,50 akan tetapi pada kadar aspal 6,00 stabilitasnya bertambah kemudian pada kadar aspal 6,50-7,00 stabilitas kembali menurun. Jadi disimpulkan stabilitas lemah dikadar aspal yang rendah karena agregat diselimuti oleh aspal yang tipis tetapi dikadar aspal 6,00 stabilitasnya tinggi karena aspal menyelimuti agregat dengan kuat akan tetapi jika aspal yang menyelimuti agregat bertambah lagi itu akan mengakibatkan stabilitas lemah. 


\section{b. VIM (Void in Mix)}

Berikut hasil uji grafik kadar aspal dengan VIM

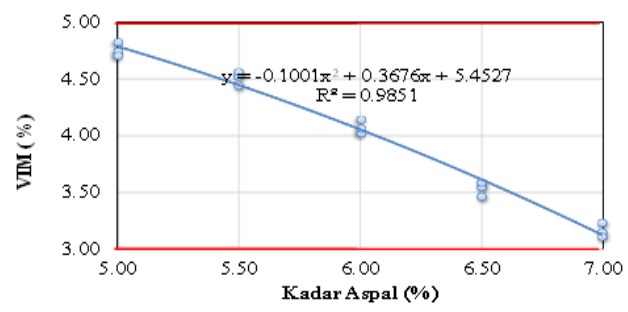

Gambar 4. Hubungan antara kadar aspal dengan VIM

Dengan melihat grafik dapat diketahui kadar aspal dan VIM itu berbanding terbalik karena semakin besar kadar aspalnya maka nilai VIM akan semakin menurun. Dengan nilai yang ada pada grafik memenuhi standard spesifikasi.

\section{c. Flow}

Berikut hasil uji grafik antara kadar aspal dengan flow.

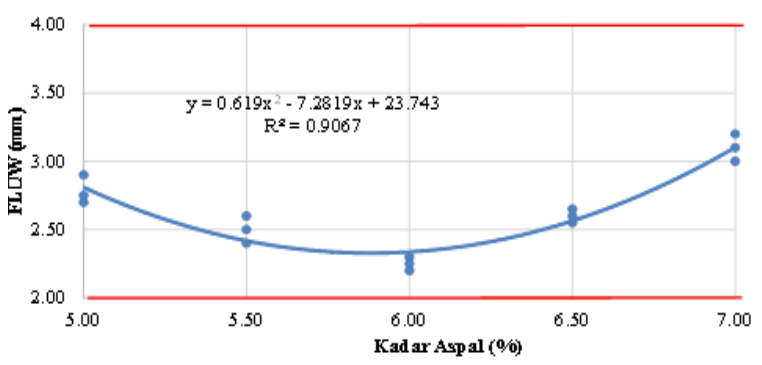

Gambar 5. Hubungan antara kadar aspal dengan Flow

Dengan melihat grafik diatas dapat diketahui bahwa kadar aspal 5,00\%-5,50\% Flow akan meningkat dan dikadar aspal 6,00 Flow menurun kemudian dikadar aspal 6,50\%-7,00\% flow meningkat kembali.

\section{d. VMA (Void in Mineral Aggregate)}

Berikut hasil uji grafik kadar aspal dengan VMA.

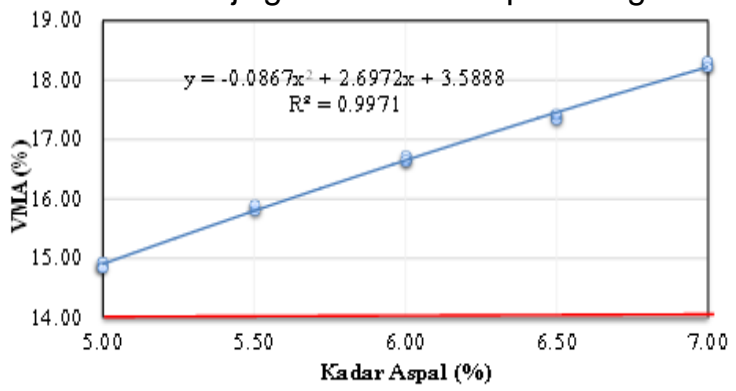

Gambar 6. Hubungan antara kadar aspal dengan VMA

Dengan memperhatikan gambar diatas dapat diketahui kadar aspal dan VMA itu berbanding lurus, karena kadar aspal yang kecil akan mengakibatkan nilai VMA ikut mengecil dan penggunaan kadar aspal yang tinggu maka nilai VMA akan menjadi tinggi juga.

e. VFB

Berikut hasil uji grafik kadar aspal dengan VFB

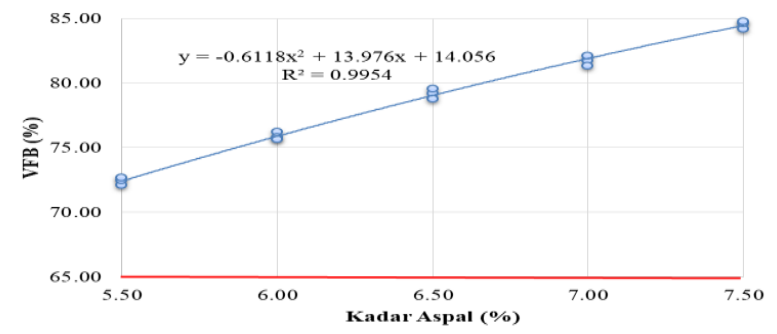

Gambar 7. Hubungan antara kadar aspal dengan VFB

Gambar diatas menunjukan bahwa kadar aspal dan VFB berbanding lurus karena penggunaan kadar aspal yang kecil akan membuat nilai VFB akan mengecil, begitu pula sebaliknya jika penggunaan kadar aspal tinggi maka nilai VFB akan tinggi juga.

\section{Penentuan Kadar Aspal Optimum}

Penentuan Kadar Aspal Optimum pada campuran AC-BC kadar aspal yang digunakan rentang pada kadar aspal 5,00\%-7,00\%. Akan tetapi kadar aspal untuk kadar aspal optimum pada campuran AC-BC dipilih yang kadar aspalnya memiliki stabilitas tinggi. Maka dari itu dipilih kadar aspal 6,00\% karena lapisan AC-BC merupakan lapisan binder atau lapisan penopang yang harus memberikan dukungan yang kuat bagi lapisan di atasnya.

\section{f. Stabilitas Marshall Sisa}

Apabila kadar aspal optimum sudah didapatkan , selanjutnya kita akan membuat sampel sesuai kadar aspal optimum yakni $6,00 \%$ yang nantinya akan direndam dalam air yang memiliki suhu $\pm 60^{\circ} \mathrm{C}$ dengan lama perendaman selama 24 jam. 
Tabel 6. Hasil pengujian indeks kekuatan sisa

\begin{tabular}{cccc}
\hline \multirow{2}{*}{ Kadar Aspal (\%) } & \multicolumn{2}{c}{ Nilai Stabilitas } & \multirow{2}{*}{ Indeks Kekuatan Sisa } \\
\cline { 2 - 3 } & Konvensional & Immertion & \\
\hline 6 & 1887,52 & 1829,89 & 96,95 \\
6 & 1916,34 & 1858,71 & 96,99 \\
6 & 1945,16 & 1887,52 & 97,04 \\
\hline Rata-rata & 1916,34 & 1858,71 & 96,99 \\
\hline
\end{tabular}

Untuk mencari nilai Stabilitas Marshall Sisa, masing-masing nilai dari Stabilitas Marshall Immersion dengan Stabilitas Marshall Konvensional dibandingkan dengan penggunaan kadar aspal $6,00 \%$ yang nantinya dikali $100 \%$ untuk mendapat hasil Stabilitas Marshall Sisa atau indeks kekuatan sisa dalam campuran. Dimana hasil dari pengujian ini yaitu 93,47\% dan dapat disimpulkan bahwa hasil uji ini memenuhi Standar Spesifikasi Bina Marga 2018 yaitu minimal $90 \%$.

\section{KESIMPULAN}

Berdasarkan dari hasil penelitian maka dapat disimpulkan sebagai berikut :

1. Karakteristik agregat dari Gunung Patangdo Kapa' Kabupaten Tana Toraja, Aspal penetrasi 60/70 dan berat jenis filler (semen) untuk campuran Laston Lapis Aus memenuhi standar Bina Marga.

2. Komposisi campuran AC-BC diperoleh agregat kasar 42,81\%, agregat halus 45,73\%, filler $5,45 \%$ dengan kadar aspal optimum $6,00 \%$.

3. Berdasrakan hasil pengujian karakteristik campuraran Asphalt Concrete - Binder Course $(A C-B C)$ melalui pengujian Marshall Konvensional dan Marshall Immersion telah memenuhi Standar Spesifikasi Umum Bina Marga 2018 yaitu $93.47 \%>90 \%$.

\section{DAFTAR PUSATAKA}

[1] Fani. L. A, Irianto, Elizabeth, dan Alpius, "Pemanfaatan Agregat Sungai Wanggar Kabupaten Nabire Sebagai Bahan Campuran AC-WC dan AC-BC," Paulus Civ. Eng. J. Ojsukipaulusacid, vol. 1, no. 2, hlm. 10-19, 2019.

[2] G. P. Palimbunga, R. Rachman, dan Alpius, "Penggunaan Agregat Sungai Batu Tiakka' dalam Campuran AC-BC," Paulus Civ. Eng. J., vol. 2, no. 2, hlm. 112-118, 2020.

[3] N. A. Salmon, Alpius, dan C. Kamba, "Pemanfaatan Batu Gunung Posi'padang Balla Kabupaten Mamasa Sebagai Campuran AC-BC," Paulus Civ. Eng. J., vol. 2, no. 2, hlm. 77-84, 2020.

[4] N. Wendani, M. Selintung, dan Alpius, "Studi Penggunaan Agregat Sungai Bittuang Sebagai Bahan Campuran AC-WC," Paulus Civ. Eng. J., vol. 2, no. 2, hlm. 138-143, 2020.

[5] R. Rachman, "Pemanfaatan Batu Gunung Bottomale Toraja Utara sebagai Campuran Laston," J. Tek. Sipil Dan Teknol., vol. 6, no. 1, hlm. 20-30, 2020.

[6] Irpan, R. Mangontan, dan Alpius, "Pemanfaatan Batu Gunung Ambeso pada Campuran AC-Base," Paulus Civ. Eng. J., vol. 2, no. 1, hlm. 58-62, 2020.

[7] D. N. Bunga, R. Rachman, dan M. Selintung, "Effect of Collision Variation towards the Index Retained Strength of Mixed Asphalt Concrete Wearing Course," Int. J. Sci. Eng. Sci., vol. 3, no. 8, hlm. 61-64, 2019, doi: 10.5281/zenodo.3408003.

[8] Sumardi, R. Rachman, dan J. Tanijaya, "Study of the Use Bagasse Ash as a Filler Replacement to Characteristics Asphalt Concrete," Int. J. Sci. Eng. Sci., vol. 3, no. 8, hlm. 65-70, 2019, doi: 10.5281/zenodo.3408011.

[9] S. A. Datu, R. Rachman, dan M. Selintung, "The Effect of Additional Sugar Palm Fibers on the Durability of Mixed Laston AC-WC," dalam The 3rd International Conference on Civil and Environmental Engineering (ICCEE), Bali, Indonesia, 2020, vol. 419, doi: 10.1088/1755-1315/419/1/012063.

[10] Direkorat Jenderal Bina Marga, Spesifikasi Umum Bina Marga 2018 untuk Pekerjaan Konstruksi Jalan dan Jembatan Divisi 6. Jakarta: Kementerian Pekerjaan Umum dan Perumahan Rakyat, 2018. 